\title{
Repair of Dental CAD/CAM Ceramics Using Resin Composite
}

\author{
RAGHAD AL-DABBAGH, Ph.D.; AZZAM SALEH, B.D.S.; AHMED ANBARI, B.D.S.; \\ OSAMA ALBADAWI, B.D.S. and YASSER ALJOHANI, B.D.S.
}

Faculty of Dentistry, King Abdulaziz University, Jeddah, Saudi Arabia

\begin{abstract}
Background: As it is seen, ceramic restorations are adopted by patients and dentists, however, the problem of chipping or fracture are made which made it crucial to repair it intraorally.

Aim of study: The aim of this study was to test the reparability of CAD/CAM feldspar ceramic (FP) in contrast to zirconia-reinforced lithium silicate ceramics with composites (Z-LSC).

Material and Methods: This study was a case-control study which was conducted in King Abdul-Aziz University Faculty of Dentistry prosthodontics laboratory. Analysis of Variance (ANOVA) was made as statistical analysis.

Results: The results are encouraging the use of Feldspar ceramic and it was concluded that Repair bond strength to feldspar ceramic could be improved when surfaces are etched with hydrofluoric acid. Zirconia-reinforced lithium silicate ceramics in not reparable using the tested conditioning protocols with composites (Z-LSC).

Conclusion: This study is to test the effect of surface conditioning on the reparability of CAD/CAM feldspar ceramic (FP) and zirconia-reinforced lithium silicate ceramics.
\end{abstract}

Key Words: Repairability - CAD/CAM Ceramics - Feldspar ceramic-Zirconia-reinforced lithium silicate ceramics.

\section{Introduction}

WITH the increase in aesthetics demand in dentistry, all-ceramic restorations are in high demand. With use, these restorations tend to chip or fracture. Intra-oral repair should be a viable clinical option.

Then, the bond strength was measured using a universal microtensile testing machine. Can penetrate surface in ANOVA. The acceptable level of significance was $p<0.05$.

Correspondence to: Dr. Raghad Al-Dabbagh, Faculty of Dentistry, King Abdulaziz University, Jeddah, Saudi Arabia

\section{Material and Methods}

King Abdul-Aziz University Faculty of Dentistry prosthodontics laboratory. CAD-CAM were used in this study feldspathic porcelain and zirconia-reinforced lithium silicate ceramics (Z-LSC) Both types of ceramics were divided into four groups based on the surface treatment protocol. Control group (C): No treatment, 5\% hydrofluoric acid etching group (HF), sand blast group (SB) and tribochemical surface treatment group. All samples were fitted with silane, and then the samples were then subjected to thermal $\left(500 \times 5^{\circ}\right.$ to $\left.55^{\circ}\right)$ [1-3]

\section{Results}

The effect of surface treatment on repaired tensile bond strength:

Hydrofluoric acid etching increased the tensile bond strength of repaired ceramic $(p<0.00)$.

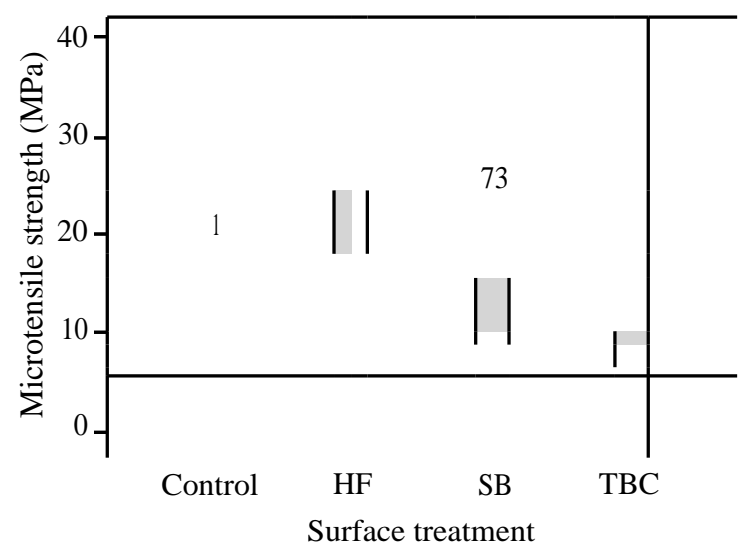

Fig. (1): Feldspar ceramic.

While conditioning Z-LSC SURFACES with $\mathrm{HF}, \mathrm{SB}$, or TBC had no effect on tensile bond strength. 


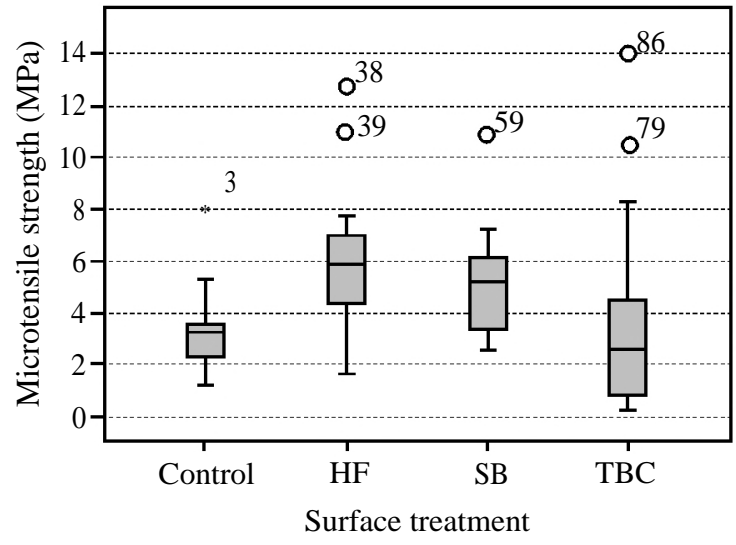

Fig. (2): Z-LSC Surfaces.

The effect of the type of ceramic on the repair bond strength was:

The repaired bond strength was higher in feldspar ceramics $(p<0.001)$.

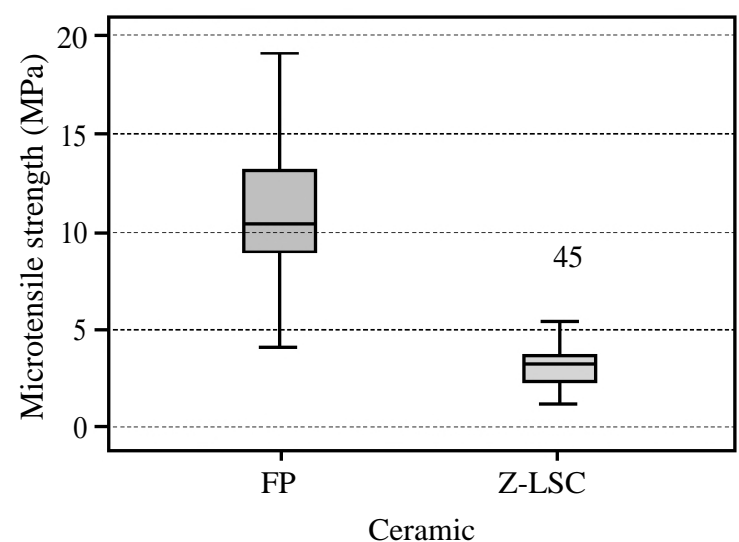

Fig. (3): FP vs Z-LSC Surfaces repaired strength among control.

The repaired bond strength was higher in feldspar ceramics $(p<0.001)$.

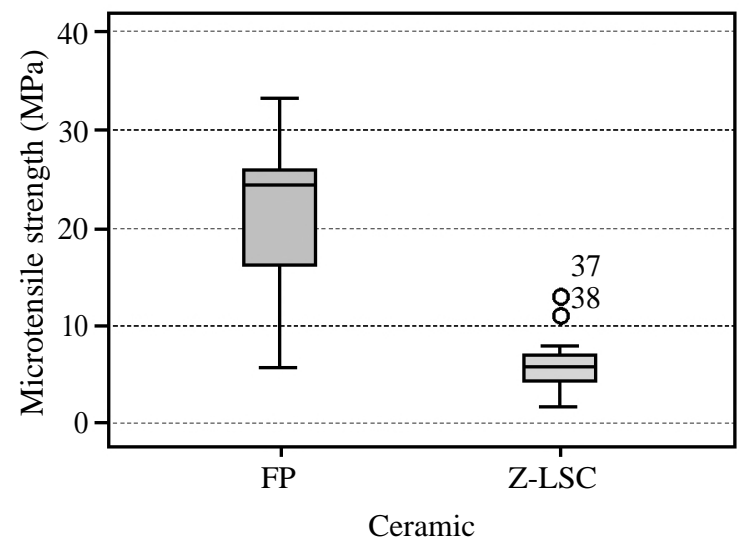

Fig. (4): FP vs Z-LSC SURFACES repaired strength among $\mathrm{HF}$.
The repaired bond strength was higher in feldspar ceramics $(p<0.001)$.

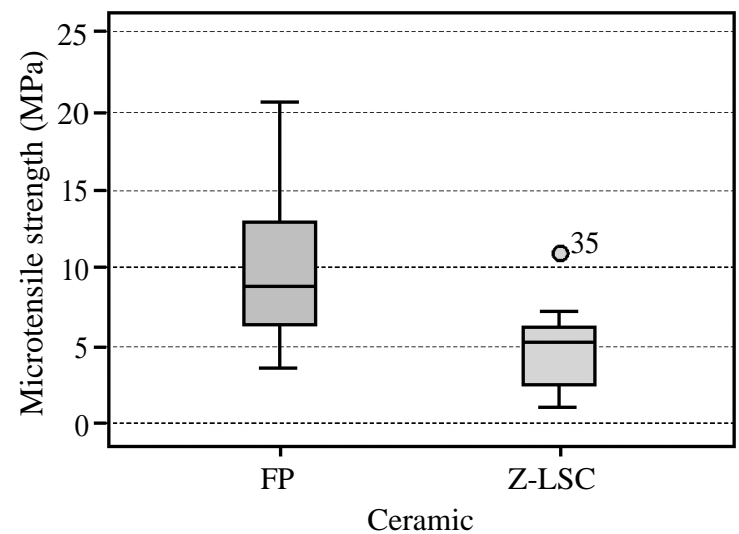

Fig. (5): FP vs Z-LSC Surfaces repaired strength among SB.

The repaired bond strength was higher in feldspar ceramics $(p<0.001)$.

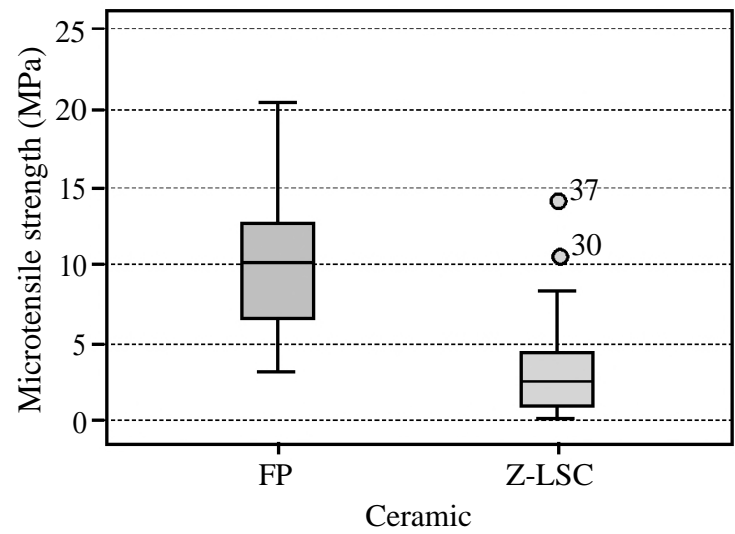

Fig. (6): FP vs Z-LSC Surfaces repaired strength among TBC.

\section{Discussion}

Repair of fractured or chipped ceramics intraorally should be an available clinical option because of various reasons including; cost effectiveness, conservative and minimal chair time. However, producing a repaired bond strength with a predictable long-term outcome is very challenging. To enhance the bond strength for repair, ceramic surfaces should be conditioned to improve the adhesion of composite to ceramics.

In this study, treating feldspar ceramics with hydrofluoric acid improved the repair bond strength which is comparable to the work done by Neis et al., [4] .

\section{Conclusion:}

Repair bond strength to feldspar ceramic could be improved when surfaces are etched with hydrofluoric acid. 
Z-LSC in not reparable using the tested conditioning protocols.

\section{References}

1- REKOW E., SILVA N., COELHO P., ZHANG Y., GUESS P. and THOMPSON V.: Performance of dental ceramics: Challenges for improvements. Journal of Dental Research, 90 (8): 937-52, 2011.

2- KIMMICH M. and STAPPERT C.F.: Intraoral treatment of veneering porcelain chipping of fixed dental restora- tions: A review and clinical application. The Journal of the American Dental Association, 144 (1): 31-44, 2013.

3- GOURAV R., ARIGA P., JAIN A.R. and PHILIP J.M.: Effect of four different surface treatments on shear bond strength of three porcelain repair systems: An in vitro study. Journal of conservative dentistry: JCD, 16 (3): 208, 2013.

4- NEIS C.A., ALBUQUERQUE N.L.G., ALBUQUERQUE I.D.S., GOMES E.A., SOUZA-FILHO C.B.D., FEITOSA V.P., et al.: Surface treatments for repair of feldspathic, leucite-and lithium disilicate-reinforced glass ceramics using composite resin. Brazilian Dental Journal, 26 (2): 152-5, 2015.

\section{CAD / CAM بروتوكول لإصلاح الأسنان المصنوعة من سيرإميك باستخلام مركب الراتنج}

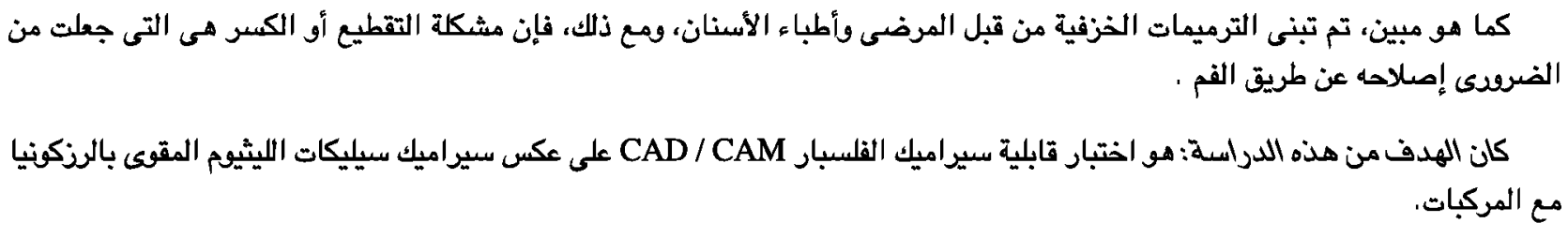

كانت هذه الدراسة دراسة الحالات والثواهد التى أجريت فى مختبر كلية طب الأسنان بجامعة الملك عبدالعزيز. تم تعليل التباين (ANOVA) كتحليل إحصائى.

النتائج: مشجعة لاستخدام السيراميك الفسباد وخلص إلى أنه يمكن تحسين قوة الرابطة لإصلاح السيراميك باستخدام الفلسبار عندما

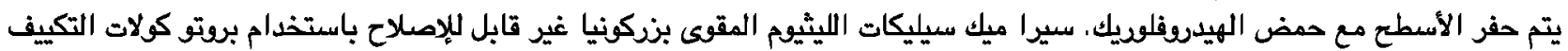

